\title{
Visual discrimination of color, pattern, and form in the Japanese quail (Coturnix coturnix japonica)'
}

FREDERICK G. FIDURA AND JENWIFER A. GRAY

MICHIGAN STATE UNIVERSITY

Although a number of recent studies (Bartlett $\&$ Liebermann, 1960; Farris, 1964; Reese E Reese, 1962; Thompson, Loomis, $\mathcal{E}$ Loomis, 1965) suggest that Japanese quail make excellent $S s$ for the behavioral laboratory, there are no parametric data on instrumental discrimination learning with this species. This study assessed the acquisition of three commonly used simultaneous discriminations; color, pattern, and form, using Coturnix quail as $S$ s. The results showed, (a) form to be the most difficult to discriminate, followed by pattern, then color, and (b) little relationship between error trials, or total trials to the criterion required for acquisition, on the three stimulus dimensions.

From time to time, a number of papers have reported favorably on the use of Japanese quail as Ss in the behavioral laboratory. Reese \& Reese (1962) for example, found the pecking response easily conditioned under less than optimal conditions, and reported success with some simple reinforcement schedules. Bartlett \& Lieberman (1960) used the bird in a pilot study in visual imitation learning. Farris (1964) has done a highly detailed analysis of behavioral development in terms of response onset and social behavior. Also, because this bird courts often and reliably, Farris was able to classically condition courting behavior in the male with the interesting finding that the components of courting behavior conditioned in the same order in which they appear developmentally. $\mathrm{T}$-maze studies using both food and water reinforcements have also been done (Farris, 1964; Thompson, Loomis, \& Loomis, 1965). In this laboratory, Japanese quail are successfully being used in studies of selective attention and complex visual discrimination. In addition to their experimental suitability, quail are smaller, easier to house and maintain, and adapt to deprivation schedules and experimental environments more quickly than pigeons (Farris, 1964; Reese \& Reese, 1962)。

As yet, no parametric data on visual discrimination in Coturnix quail have been reported. This study assessed the acquisition of three commonly used visual stimulus dimensions: color, pattern, and geometric form using Japanese quail as Ss.

Subjects

The Ss were 14 male and eight female Japanese quail, 50-60 days of age.

Apparatus

The apparatus consisted of a commercial operant chamber fitted with two pecking keys. The chamber was modified by raising the floor $2-1 / 8$ in. and by mounting a multiple stimulus projector behind each key. Presenta- tion of stimuli, reinforcement, and the overall functioning of the apparatus was programmed by means of a punched-paper tape-reading device operating through a system of relays and timers.

\section{Procedure}

The Ss were maintained at $75-80 \%$ ad libitum body weight. The pecking response was well established by requiring the Ss to peck an amber lighted key vs, a simultaneously present non-lighted key (randomized for position) for 200 food reinforcements. An amber rather than a white lighted key was used to avoid later generalization to a small white circle used as a discriminative stimulus in the form discrimination. Pilot research showed that pre-training with amber as compared to white, had no effect on a later red-green color discrimination.

Following these 200 pre-training trials, each Slearned three discriminations. Both the reinforced and the nonreinforced stimuli were presented simultaneously using a discrete trial procedure. The three binary stimulus dimensions and their attributes were as follows:

\begin{tabular}{lll} 
& Reinforced & Non-reinforced \\
\cline { 2 - 3 } Color & Red & Green \\
Pattern & Horizontal lines & Vertical lines \\
Form & Triangle & Circle
\end{tabular}

The colors were equated for physical brightness, and the order in which the discriminations were learned was randomly assigned. A response to either key terminated the stimulus lights and rendered the keys inoperative for $8 \mathrm{sec}$. A food hopper was available for $5 \mathrm{sec}$. following a correct response. To avoid perseveration on one key with resulting $50 \%$ partial reinforcement, a modified correction technique was used. On error trials, the stimulus sequencing system was not advanced, consequently, the stimulus attributes maintained the same relative position on the next trial. Correct, error, and total responses were recorded. The criterion of acquisition was 15 consecutive correct responses.

\section{Results}

Table 1 presents the mean number of total trials and the mean number of error trials to the first criterion

Table 1. Means and standard deviations of total and error trials to the first criterion trial for each dimension $(N=22)$

\begin{tabular}{lrrrrrr} 
& \multicolumn{2}{c}{ Color } & \multicolumn{2}{c}{ Pattern } & \multicolumn{2}{c}{ Form } \\
& Total & Error & Total & Error & Total & Error \\
\hline M & 27.5 & 7.5 & 123.5 & 47.6 & 360.6 & 159.3 \\
SD & 26.9 & 7.8 & 80.2 & 31.7 & 180.4 & 76.6 \\
\hline
\end{tabular}


Table 2. Intercorrelations of error trials and total trials for the three dimensions

(Entries above the diagonal are for total responses, entries below for error responses.)

\begin{tabular}{lccc} 
& Color & Pattern & Form \\
\hline Color & 1.00 & .16 & .28 \\
Patfern & .20 & 1.00 & .01 \\
Form & .29 & .15 & 1.00 \\
\hline
\end{tabular}

trial, together with their standard deviations. There is an obvious increase in both mean error and mean total trials to the first criterion trial and an increase in variability for color, pattern, and form respectively. Further, no significant order effect was found for any of these dimensions.

Table 2 presents the intercorrelations of the three dimensions for error and total trials to the first criterion trial. The entries above the diagonal are the intercorrelations of total trials to the first criterion trial, while those below the diagonal indicate the intercorrelations among error trials. None of the correlations is significant at the .1 level.

The increase in trials to the first criterion trial reflects the increasing difficulty of color, pattern, and form, respectively, as does the increase in variability. Clearly, in terms of acquisition, color is easiest to discriminate, followed by pattern, then form. These findings agree with the results of other avian studies, such as those of Zeigler (1963) and others, concerning the relative difficulty of the stimuli used. In the few species of birds tested, color discriminations are usually least difficult to learn, followed by pattern discriminations, then geometric form. Since most other studies of avian discrimination have used a somewhat different design, no cross species comparisons can be made.
The low intercorrelations among the dimensions are more difficult to interpret. Since each S learned all three dimensions, higher correlations might have been expected; a bird which did well on one discrimination, given any generalized learning ability should have done well on all of them, relative to the other Ss. An examination of the scatter plot showed no curvilinear relationship, and further examination of the data showed that, in fact, the Ss obviously were changing positions from distribution to distribution. It seems unlikely then, that these low correlations were due to statistical artifact. It appears that the acquisition of these three discriminations is a function of several independent processes. As part of an on-going research program in selective attention, where one of the above dimensions is relevant and must be learned in the presence of the other two dimensions which are irrelevant, we are assessing this latter possibility.

\section{References}

Bartlett, L. M., \& Liebermann, E. Possible visual imitation in the Coturnix quail. Proceedings of the 57 th Annual Meeting of American Zoologists. In Anat. Rec., 1960, 138, 333. (Abstract)

Farris, H. E. Behavioral development, social organization, and conditioning of courting behavior in the Japanese quail (Coturnix coturnix japonica). Unpublished doctoral dissertation, Michigan State University, 1964.

Reese, Ellen, P., \& Reese, T. W. The quail, Coturnix coturnix japonica, as a laboratory animal. J. exp. Anal. Behav., 1962, 5, 265-270.

Thompson, M. E., Loomis, Marg E., \& Loomis, Lou Ann. Response variability in the quail (Coturnix coturnix japonica). Psychon. Sci., 1965, 3, 519-520.

Zeigler, H. P. Effects of endbrain lesions on visual discrimination learning in pigeons. J. comp. Neur., 1963, 120, 161-181.

\section{Note}

1. This paper was presented by the first author at the Midwest Psychological Association Convention, May 5, 1966. 